\title{
Paediatric Aspects of the Early Discharge of Maternity Patients
}

\author{
M. W. ARTHURTON,* M.D., M.R.C.P., D.C.H. ; F. N. BAMFORD, $†$ M.B., CH.B., D.C.H., D.P.H.
}

Brit. med.7., 1967, 3, 517-520

Planned early discharge of mothers and babies from St. Luke's Maternity Hospital, Bradford, has been taking place since 1958. The purpose of this paper is to describe the effect it has had on child health in the city, and, in particular, to consider its safety and acceptability from a paediatric point of view.

Theobald $(1959,1962)$ depicted the form and purpose of the "Bradford experiment," and Douglas et al. (1961) have published the results of the scheme from its inception until the end of 1960. The results of early discharge elsewhere have been described by Hellman et al. (1962) and Pinker and Fraser (1964).

Our review covers a period of seven years from January 1959 to December 1965, during which time 9,718 babies were discharged within 72 hours of birth. It is believed that up to the present this represents the greatest numerical experience of planned early discharge in Great Britain. The survey does not include babies taken home early against advice or those discharged to other units, nor to areas outside the city boundary. Full responsibility for neonatal care was accepted by the paediatric department in August 1962.

\section{Results}

The total number and the proportion of babies discharged within 72 hours to the city area during each of the seven years is shown in Table $\mathrm{I}$.

\begin{tabular}{l|c|c|c|c|c|c|c|c|c}
\multicolumn{8}{c}{ TABLE I.-Babies } & Discharged Within 72 Hours \\
\hline & 1959 & 1960 & 1961 & 1962 & 1963 & 1964 & 1965 & Total \\
\hline $\begin{array}{l}\text { No. of babies } \\
\text { discharged early }\end{array}$ & 922 & 1,176 & 1,358 & 1,350 & 1,659 & 1,562 & 1,681 & 9,718 \\
$\begin{array}{c}\text { Proportion of total } \\
\text { hospital births dis- } \\
\text { charged early (\%).. }\end{array}$ & $37 \cdot 3$ & 37.0 & $41 \cdot 9$ & $39 \cdot 4$ & $48 \cdot 7$ & $44 \cdot 1$ & $47 \cdot 6$ & $41 \cdot 6$ \\
\hline
\end{tabular}

\section{Mortality}

Fig. 1 gives the perinatal mortality rate of Bradford in comparison with the national rate. Of the 9,718 babies who were discharged early 8 (0.82 per thousand) died before they reached the age of 11 days. Out of a total of 15,887 babies born on the district during the same period 20 died between the ages of 2 and 10 days inclusive, giving a comparable mortality rate of 1.26 per thousand. The difference between the two groups is not statistically significant (S.E. (difference), $0.40 ; \mathrm{P}=0.24)$.

Details of the eight babies from the early discharge group who died are as follows:

Case 1.-Tentorial tear: spontaneous occipitoposterior delivery; fourth child ; birth weight $9 \mathrm{lb}$. (4.080 g.). Discharged by obstetric registrar at age 34 hours; readmitted on third day and died next day.

Case 2.-Atrial septal defect with hypoplastic left ventricle and aorta: normal delivery; second child; birth weight $6 \mathrm{lb} .2 \mathrm{oz}$. $(2.780$ g.). Discharged by obstetric house-surgeon at age 39 hours; readmitted on eighth day in cardiac failure but with normal heart sounds; died on the following day.

- Consultant Paediatrician, Bradford.

† Principal Medical Officer in Child Health, Bradford.
Case 3.-Perforated caecum with peritonitis: normal delivery; third child; birth weight $7 \mathrm{Ib} .4$ oz. (3,290 g.). Discharged by obstetric house-surgeon at age 29 hours. Vomited blood on the second day; readmitted on the fifth day because of persistent vomiting. Immediate laparotomy with exteriorization of caecum and peritoneal drainage; died five hours later.

Case 4.-Ventricular septal defect: normal delivery; third child; birth weight $8 \mathrm{lb} .5 \mathrm{oz}$. (3,770 g.). Discharged by obstetric

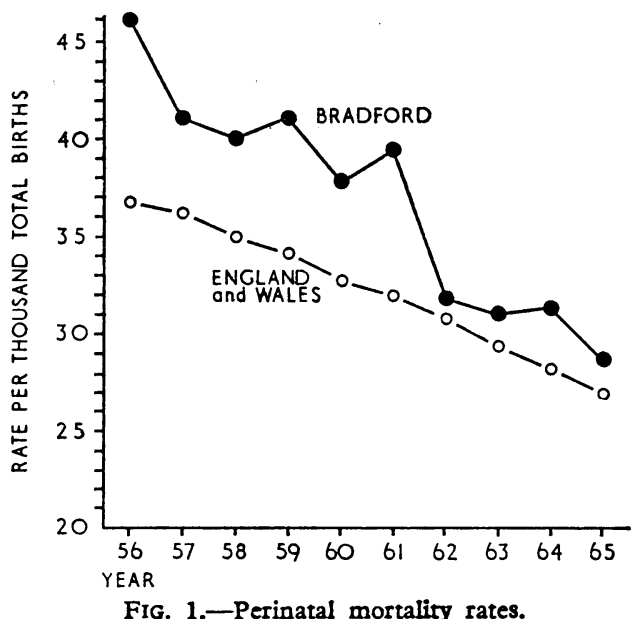

registrar at age 28 hours; readmitted in cardiac failure with a cardiac murmur on the sixth day of life; died on the following day.

Case 5.-Bronchopneumonia: normal delivery; fourth child; birth weight $6 \mathrm{lb}$. $(2,720 \mathrm{~g}$.). Discharged by paediatric senior houseofficer at age 32 hours. Midwife subsequently refused admission to house; died at home on the third day.

Case 6.-Fallot's tetralogy: shoulder presentation corrected to vertex ; third child ; birth weight $8 \mathrm{lb} .6 \mathrm{oz}$. (3,800 g.). Discharged by paediatric registrar at age 27 hours ; readmitted on sixth day of life with peripheral cyanosis, rapid pulse, enlarged heart, but no cardiac murmur or signs of failure; died next day. Necropsy also revealed a small cerebral haemorrhage.

Case 7.-Bronchopneumonia : normal delivery ; first child ; birth weight $7 \mathrm{lb}$. $(3,175$ g.). Discharged by paediatric registrar at age 39 hours. Died at home on the ninth day of life.

Case 8.-Left adrenal haemorrhage: normal delivery; third child ; birth weight $6 \mathrm{lb} .5 \mathrm{oz} .(2,865 \mathrm{~g}$.). Discharged by paediatric senior house-officer at age 36 hours. Readmitted on the same day; died of peripheral circulatory failure a few hours later.

In addition to the eight babies described above nine who were discharged early died between the twelfth and twentyninth days, inclusive. The causes of death were as follows:

Bronchopneumonia f.. $\ldots \quad 6$ babies aged 15 to 25 days

Transposition of great vessels $\ldots . \quad 1$ baby aged 13 days

Gastroenteritis $\quad \ldots \quad \ldots \quad \ldots \quad 1$ baby aged 21 days

Tentorial tear ... $\ldots . \ldots 1$ baby aged 15 days

The cause of death was confirmed at necropsy in every case.

\section{Morbidity}

Of those babies who were discharged early 85 (8.74 per thousand) were readmitted to hospital within the first 10 days, 
compared with 145 (9.12 per thousand) babies of the same age born on the district and admitted to hospital between the ages of 2 and 10 days inclusive. This difference is not significant (S.E. (difference), $1.21 ; \mathrm{P}=0.75$ ).

The age at the time of readmission of early discharge babies is shown in Fig. 2.

Table II shows the cumulative percentage of early discharge babies readmitted between the ages of 1 and 10 days inclusive.

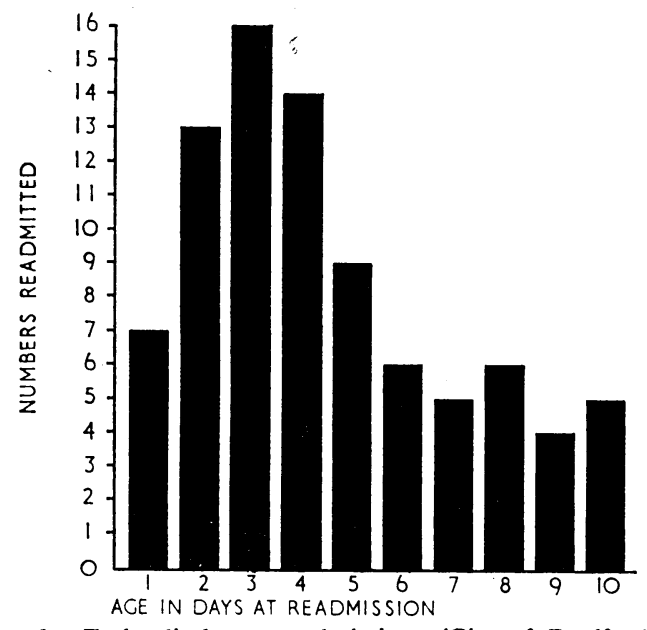

Frg. 2.-Early discharge readmissions (City of Bradford).

\begin{tabular}{ll|l|l|l|l|l|l|l|l|l|l} 
TABLE II \\
\hline $\begin{array}{l}\text { Age (tlays) } \\
\begin{array}{l}\text { Cumulative \% of } \\
\text { @dmissions }\end{array}\end{array}$ & 1 & 2 & 3 & 4 & 5 & 6 & 7 & 8 & 9 & 10 \\
\hline
\end{tabular}

The reasons for readmission of babies are shown in Table III and comparable figures are given for babies of the same age who were born at home and required admission to hospital.

TABLE III.-Reasons for Readmission

\begin{tabular}{|c|c|c|}
\hline $\begin{array}{c}\text { Diagnosis on } \\
\text { Admission/Readmission }\end{array}$ & $\begin{array}{c}\text { No. of Early } \\
\text { Discharge Babies }\end{array}$ & $\begin{array}{l}\text { No. of } \\
\text { Domiciliary Bahies }\end{array}$ \\
\hline 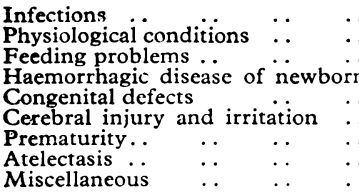 & $\begin{array}{rr}21 & (24 \cdot 7 \%) \\
15 & (17 \cdot 6 \%) \\
9 & (10 \cdot 6 \%) \\
9 & (10 \cdot 6 \%) \\
8 & (9 \cdot 4 \%) \\
5 & (5.9 \%)\end{array}$ & $\begin{aligned} 41 & (28 \cdot 2 \%) \\
10 & (6.9 \%) \\
16 & (11.0 \%) \\
9 & (6.2 \%) \\
18 & (12.4 \%) \\
13 & (9.0 \%) \\
7 & (4.8 \%) \\
2 & (1.4 \%) \\
29 & (20.1 \%)\end{aligned}$ \\
\hline
\end{tabular}

Any early discharge baby readmitted before the age of 48 hours was included in Table III, whereas domiciliary delivered babies admitted before that age were excluded from consideration.

Babies discharged before the age of 24 hours required readmission significantly more of ten than those sent home on the second day. During the period covered by Craig and Muirhead (1967) $3.7 \%$ of mothers were discharged before 24 hours, but $17.6 \%$ of the babies readmitted to hospital in the same period had been discharged on the first day of life (S.E. (difference) $=5.33 \%$ ).

Table III gives no indication of the incidence of minor morbidity. An attempt was made to assess this by an analysis of midwives' medical aid request forms, but the differing practice of general practitioners in neonatal visiting and the variable experience of individual midwives made the results inexact. However, during the last two years of the survey $7.4 \%$ of the domiciliary group and $2.9 \%$ of the early discharge babies were the subject of medical aid calls between the second and tenth days of life.

\section{Breast-feeding}

A postal questionary was sent to all women delivered in Bradford in the first six months of 1964 with the exception of those cases where there was an obstetric, paediatric, or social abnormality which could interfere with the establishment or maintenance of breast-feeding. The number of "normal" confinements in the long-stay group was at first insufficient for statistical comparison, and this group was enlarged by the inclusion of similar women delivered during the following 18 months. A total of 743 patients returned the questionary ; 515 of these were delivered on the district; 163 stayed in hospital for less than 72 hours and 65 for more than 72 hours (Table IV).

\begin{tabular}{c|c|c|c} 
TABLE IV.-Breast-feeding \\
\hline & Domiciliary & $\begin{array}{c}\text { Hospital } \\
\text { Short-stay }\end{array}$ & $\begin{array}{c}\text { Hospital } \\
\text { Long-stay }\end{array}$ \\
\hline $\begin{array}{c}\text { Percentage of women breast- } \\
\text { feeding for one week or more }\end{array}$ & 57.9 & 67.5 & 73.8 \\
$\begin{array}{c}\text { Percentage of women breast- } \\
\text { feeding for six weeks or more }\end{array}$ & 21.0 & 31.9 & 23.1
\end{tabular}

We tried to find out what caused women in each of the groups to discontinue breast-feeding. They were given a choice of six reasons, and were asked to select the one that applied to them (Table V).

TABLE V

\begin{tabular}{|c|c|c|c|c|c|c|}
\hline & \multicolumn{3}{|c|}{$\begin{array}{l}\text { Reasons for Breast-Feeding } \\
\text { Less Than One Week (\% } \\
\text { of Reasons Given) }\end{array}$} & \multicolumn{3}{|c|}{$\begin{array}{l}\text { Reasons for Stopping } \\
\text { Breast-Feeding After the } \\
\text { First Week ( } \% \text { of } \\
\text { Reasons Given) }\end{array}$} \\
\hline & District & $\begin{array}{c}\text { Hospital } \\
\text { Short-- } \\
\text { stay }\end{array}$ & $\begin{array}{c}\text { Hospital } \\
\text { Long- } \\
\text { stay }\end{array}$ & District & $\mid \begin{array}{c}\text { Hospital } \\
\text { Short- } \\
\text { stay }\end{array}$ & $\begin{array}{c}\text { Hospital } \\
\text { Long- } \\
\text { stay }\end{array}$ \\
\hline $\begin{array}{l}\text { Preferred to bottle-feed } \\
\text { Returned to work } \\
\text { Illness . } \\
\text { Not enough milk } \\
\text { Pain or difficulty } \\
\text { Baby old enough to stop }\end{array}$ & $\begin{array}{r}54 \cdot 1 \\
1 \cdot 0 \\
1 \cdot 9 \\
19 \cdot 3 \\
23 \cdot 7 \\
-\end{array}$ & $\begin{array}{r}38 \cdot 3 \\
1 \cdot 7 \\
3 \cdot 3 \\
20 \cdot 0 \\
36 \cdot 7 \\
\end{array}$ & $\frac{26 \cdot 7}{2 \overline{7}}$ & $\begin{array}{r}12 \cdot 3 \\
1 \cdot 6 \\
3 \cdot 8 \\
49 \cdot 3 \\
21 \cdot 4 \\
11 \cdot 6\end{array}$ & $\begin{array}{r}11 \cdot 6 \\
\frac{5 \cdot 4}{45 \cdot 5} \\
23 \cdot 2 \\
14 \cdot 3\end{array}$ & $\begin{array}{r}21 \cdot 3 \\
2 \cdot 1 \\
61 \cdot 7 \\
10 \cdot 6 \\
4 \cdot 3\end{array}$ \\
\hline
\end{tabular}

\section{Discussion}

Bradford is an industrial city which had a high incidence of toxaemia of pregnancy and a perinatal mortality rate considerably higher than the national average. The original purpose of planned early discharge was to release hospital beds for the treatment of toxaemia without reducing the number of hospital confinements. Since the inception of the scheme there has been an absolute improvement in perinatal mortality and also an improvement relative to the national rate (Fig. 1).

Better facilities for the treatment of toxaemia might have been expected to result in a reduction in the number of premature births, and it is disappointing that this has not occurred. There has, however, been a decrease in the proportion of premature babies of low birth weight-for example, those of $3 \mathrm{lb} .4 \mathrm{oz}$. (1.475 g.) or less-the total number of which has remained constant despite a rising birth rate.

Unfortunately it is difficult to be certain of the exact effect of early discharge because the figures have been confused by a changing population structure during the seven years of the study, but it is clear that the scheme has had no serious adverse effect and may have contributed to an improvement in child health.

Deaths among babies who were the subject of early discharge have been compared with the number who died between the ages of 2 and 10 days, inclusive, after domiciliary confinement. We believe that this comparison is valid, since domiciliary confinement has been the only practicable alternative for the majority of mothers in the city. 
There is no evidence that early discharge offers any advantage for the individual baby as compared with staying in hospital for 10 days, and in fact there are additional risks partly attributable to difficulties in neonatal diagnosis. Some congenital defects and cerebral lesions do not show themselves within the first 48 hours, nor, in the case of one of our late deaths, within the normal 10-day lying-in period. Though it was undesirable, on general grounds, to have discharged the eight babies who subsequently died, it is unlikely that early discharge adversely affected the chances of survival of Cases 1 and 2. Early discharge was ill-advised in Cases 3 and 6. None of the nine deaths occurring after 10 days could be related to early discharge.

The longer a baby remains in hospital the less likely it is that pathological lesions will be undetected before discharge. It is preferable to avoid the need for readmission, and in our experience this would be reduced by $59 \%$ if mothers and babies left hospital on the fifth day (Fig. 2). Unfortunately, this would not be practicable without a fundamental reorganization of the maternity services. At present such an arrangement might lead to a false sense of security, because the interest taken by domiciliary midwives could be inversely proportional to the length of hospital stay of the baby. Furthermore, it would be sensible to discharge breast-fed babies as early as possible so that the early phases of feeding could be supervised by one adviser.

The incidence of feeding problems severe enough to warrant readmission was virtually the same in the two groups of babies, though a survey by members of the College of General Practitioners (1966) did show a higher incidence of minor feeding problems in their early discharge group. In our review of the early discharge babies readmitted five were underfed on the breast, two mothers lost their milk owing to emotional disturbance, and in one case faulty technique in artificial feeding was noted.

It was noticeable and understandable that in the early years of the survey a greater proportion of early discharge babies were readmitted with physiological conditions, including swallowed-blood syndrome, vaginal bleeding, urates in the urine, and physiological jaundice. There was a statistically significant difference $(P<0.05)$ in admission rates for these conditions between the early discharge and domiciliary groups (see Table III).

As might have been anticipated, cases of haemorrhagic disease were readmitted early, two-thirds of them by the third day and all of them by the fifth day of life.

Babies with congenital defects who were readmitted consisted of five with congenital heart disease and three with hiatus hernia. In only one case of the former was a murmur heard on readmission. Careful perusal of admissions to the genitourinary department during the period of the survey failed to reveal any missed cases of obstructive lesions of the genitourinary tract, though such cases could easily be missed in the first two days of life.

Two cases of subarachnoid haemorrhage (one fatal), one case of subdural haemorrhage, and two babies with cerebral irritation were readmitted. The fatal case was an occipitoposterior delivery, and in one case of cerebral irritation delivery was by low forceps. Otherwise the confinements were normal. The number of cerebral complications did not differ significantly between the two groups of babies.

Unfortunately, owing to differences in methods of ascertainment by different observers and lack of strictly comparable groups, it was not possible to compare the incidence of infection in babies delivered at home, those discharged early, and those remaining in hospital for 10 days, many of the latter group being abnormal deliveries. The readmission rates for infection in the first two groups did not differ significantly. It is noteworthy that during the period of the survey four cases of gonococcal ophthalmia of late onset were observed in babies staying in hospital for 10 days.

Included in the miscellaneous group were convulsions (4), choking attacks (3), anal excoriation (2), haemolytic disease of the newborn due to rhesus incompatibility (2), and one case each of left adrenal haemorrhage (fatal), congenital spherocytic anaemia, hypothermia, meconium plug, perforated caecum (fatal), pyloric stenosis, and urticaria. No cause was found for the convulsions, and the deliveries of all these cases were normal. The two babies with haemolytic disease and one with meconium plug were erroneously discharged by junior hospital staff. Reference has already been made to the fatal cases.

Prior consultation between general practitioner and paediatrician would have made unnecessary the readmission of 18 $(21 \%)$ cases in the early discharge group. A further eight babies who were readmitted had been erroneously discharged early because of faulty judgement. Thus there remained 59 babies in our series whose readmission would have been unavoidable, and it is therefore desirable to have special accommodation reserved so that mothers and babies can be readmitted together.

The Cranbrook Report (Ministry of Health, 1958) and the British Medical fournal (1964) suggest that early discharge adversely affects breast feeding, but this is contrary to our experience. In this city, of "normal" women delivered in hospital a greater proportion breast-fed for one week or longer than did women confined at home, and relatively more of them continued to feed for six weeks or longer. The differences between the short-stay and domiciliary groups are highly significant and pertain to all ages. It was shown that, though more of the younger mothers start to breast-feed-that is, feed for one week or more-a greater proportion of older mothers become established breast-feeders-that is, feed for six weeks or more. Social class was not significant in determining the number of women starting to breast-feed, but feeding was shown to become established more frequently in social groups I and II. The difference between the early discharge and long-stay hospital groups was not statistically significant.

A disturbing finding in the breast-feeding survey was that relatively more women delivered in hospital discontinued feeding after less than one week because of pain or difficulty (see Table V). Of those confined in hospital who fed for one week or longer the proportions in the early discharge and long-stay groups are about equal, which suggests that the disparity is due to an adverse influence in hospitals and that it is not assisted by the mother remaining for 10 days.

An early discharge scheme of the type that has been in operation in Bradford during the past seven years can be operated with advantage to the neonate, and he suffers no disadvantages as compared with the baby born on the district. We would emphasize, however, that the arrangements have to be planned in advance, and that close and continuing co-operation is necessary between all people concerned. Success depends on the competence and reliability of midwives, nurses, and junior medical staff, who carry out 10 or more routine neonatal examinations every day of the year. An efficient neonatal follow-up clinic is vital, as is the willingness of the paediatrician to deal promptly and personally with the medical and social consequences of neonatal abnormality. Provided that this degree of effort is made, the scheme can be safe and effective.

\section{Summary}

During 1959 to 1955 , inclusive, a total of 9,718 babies were discharged from hospital within 72 hours of birth. An improvement in perinatal mortality has been described, and the mortality and morbidity experience of "early discharge" babies has been compared with those born at home during the same period. The difference between the two groups was not statistically significant. An inquiry into breast-feeding in the domiciliary, 
early discharge, and long-stay hospital patients is recorded; it has shown that mothers confined in hospital begin to feed their babies and become established breast-feeders more of ten than do women delivered at home.

We wish to thank Dr. A. P. Roberts for permission to review cases in his care ; Miss G. Clayton, Matron of St. Luke's Maternity Hospital, and Miss E. R. Entwhistle, Supervisor of Midwives, for their invaluable help on numerous occasions; and Dr. G. Hill for statistical advice. We wish to pay tribute to a very loyal junior staff.

\section{REFERENCES}

Brit. med. 7., 1964, 2, 70.

College of General Practitioners, Bradford Group (1966). Lancet, 1, 536.

Craig, G. A., and Muirhead, J. M. B. (1967). Brit. med. 7., 3, 520.

Douglas, J., Edgar, W., and Horne, K. (1961). Med. Offr, 106, 333.

Hellman, L. M., Kohl, S. G., and Palmer, J. (1962). Lancet, 1, 227.

Ministry of Health (1958). Report of the Maternity Services Committee (Cranbrook Report). H.M.S.O., London.

Pinker, G. D., and Fraser, A. C. (1964). Brit. med. 7., 2, 99.

Theobald, G. W. (1959). Ibid., 2, 1364.

- (1962). Lancet, 1, 735.

\title{
Obstetric Aspects of the Early Discharge of Maternity Patients
}

\author{
G. A. CRAIG, ${ }^{*}$ M.B.E., F.R.C.S., F.R.C.o.G. ; J. M. B. MUIRHEAD, ${ }^{*}$ M.B., B.CH., M.R.C.o.G.
}

\section{Brit. med. F., 1967, 3, 520-522}

It is now nine years since planned early discharge of the normal mother and normal baby on the second day of the puerperium was commenced in Bradford. The scheme has since been in continuous operation, and to date approximately 13,000 puerperal women have been managed in this way. Theobald $(1959,1962)$ and Douglas et al. (1961) described the reasons for and the initial planning of the scheme, and recorded its early results. In 1966 members of the College of General Practitioners (Bradford group) reported on a survey of 100 early discharge cases.

Five thousand consecutive case records have been analysed in order to show the types of patients that have participated in the scheme. Abnormalities that occurred but which were not thought sufficiently important to warrant retaining the patient in hospital for longer than 60 hours have been recorded. The purpose of the paper is to present these results, and it also includes a discussion of our experience.

\section{Patients Discharged Early}

Of the 5,000 patients whose records were analysed $70 \%$ were booked for hospital confinement and 30\% were emergency admissions either during the antenatal period or during labour. The age distribution is recorded in Table $I$. The number of

TABle I.-Age Distribution of Patients Discharged Early

\begin{tabular}{|c|c|c|c|c|}
\hline \multicolumn{3}{|c|}{ Age Group } & Primigravidae & Multigravidae \\
\hline $\begin{array}{l}\text { Under } 20 \text { years } \\
20-24 \text { years } \\
25-29 \text { years } \\
30-34 \text { years } \\
35 \text { years and over }\end{array}$ & $\begin{array}{ll}. & \cdots \\
. & \cdots \\
\cdots & \cdots \\
. & \cdots\end{array}$ & $\begin{array}{l}\cdots \\
\cdots \\
\cdots \\
\cdots\end{array}$ & $\begin{array}{l}421(8 \cdot 4 \%) \\
644(12 \cdot 9 \%) \\
320(6 \cdot 4 \%) \\
136(2 \cdot 7 \%) \\
30(0.6 \%)\end{array}$ & $\begin{array}{r}89(1.8 \%) \\
695(13.9 \%) \\
1,028(20.6 \%) \\
848(17.0 \%) \\
789(15.8 \%)\end{array}$ \\
\hline
\end{tabular}

TABle II.-Parity Distribution of Patients Discharged Early

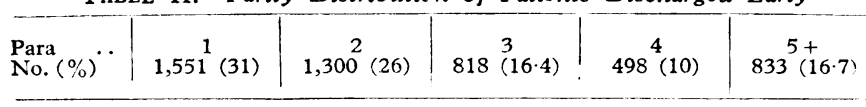

\begin{tabular}{|c|c|c|c|c|c|c|}
\hline \multirow{2}{*}{ Duration of Stay } & \multicolumn{2}{|c|}{ Primiparae } & \multicolumn{2}{|c|}{ Multiparae } & \multicolumn{2}{|c|}{ Total } \\
\hline & No. & $\%$ & No. & $\%$ & No. & $\%$ \\
\hline $\begin{array}{l}\text { Patients discharged in } \\
\text { less than } 24 \text { hours }\end{array}$ & 56 & $1 \cdot 1$ & 127 & 2.5 & 183 & 3.7 \\
\hline $\begin{array}{l}\text { Patients discharged in } \\
24-36 \text { hours. } \\
\text { P. }\end{array}$ & 1,094 & 21.9 & 2,450 & $49 \cdot 0$ & 3,544 & $70 \cdot 9$ \\
\hline $\begin{array}{c}\text { Patients discharged in } \\
36-60 \text { hours.. }\end{array}$ & 401 & $8 \cdot 0$ & 872 & $17 \cdot 4$ & 1,273 & $25 \cdot 4$ \\
\hline
\end{tabular}

women in each parity group is shown in Table II. The length of stay in hospital of the 5,000 patients is given in Table III.

The original policy was to discharge on the second day those mothers and babies whose condition did not seem to justify further hospital care. A number of women who had had abnormalities during labour or at the time of delivery have participated in the scheme. The incidence of intrapartum complications in the 5,000 patients whose records were analysed is shown in Table IV. The complications that occurred at the time of delivery in patients discharged early are recorded in Table V.

TABLE IV.-Intrapartum Complications in Patients Discharged Early

\begin{tabular}{c|c|c}
\hline Intrapartum Complication & Primigravidae & Multigravidae \\
\hline Artificial rupture of membranes $\ldots$ & $512(10 \cdot 2 \%)$ & $916(18 \cdot 3 \%)$ \\
$\begin{array}{l}\text { Oxytocin drip } \\
\text { Pyrexia } 99-99 \cdot 8^{\circ} \mathrm{F} .\left(37 \cdot 2-37 \cdot 7^{\circ} \mathrm{C} .\right)\end{array}$ & $84(1 \cdot 7 \%)$ & $197(3.9 \%)$ \\
on two or more occasions & $17(0.3 \%)$ & $38(0.8 \%)$ \\
Pyrexia $100^{\circ} \mathrm{F} .\left(37 \cdot 8^{\circ} \mathrm{C}.\right)$ and over & $3(0.06 \%)$ & $9(0 \cdot 2 \%)$ \\
\hline
\end{tabular}

TABle V.-Complications at Time of Delivery in Early Discharge

\begin{tabular}{|c|c|c|}
\hline Complication & Primigravidae & Multigrav:dae \\
\hline 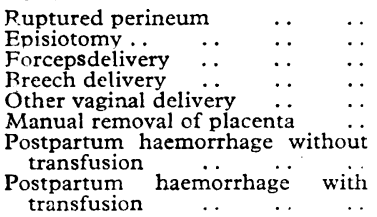 & $\begin{array}{l}520(10 \cdot 4 \%) \\
533(10.7 \%) \\
185(3.7 \%) \\
27(0.5 \%) \\
16(0.3 \%) \\
9(0.2 \%) \\
49(1.0 \%) \\
2(0.04 \%)\end{array}$ & $\begin{array}{c}866(17.3 \%) \\
324(6.5 \%) \\
79(1.6 \%) \\
69(1.4 \%) \\
31(0.6 \%) \\
30(0.6 \%)\end{array}$ \\
\hline
\end{tabular}

\section{Hospital Organization}

The early discharge scheme has resulted in a considerable increase in the work done in the hospital. St. Luke's Maternity Hospital is the only maternity hospital in Bradford. It was designed to manage approximately 1,500 confinements a year. Before the introduction of the scheme in 1958 this figure had risen to 2,000 a year and since then it has continued to rise until in 1964 it almost reached 4,000. Such an increase imposes a very severe strain on all members of the hospital staff, particularly those engaged in the labour ward. In such circumstances it is difficult to maintain standards and the continuous

* Consultant Obstetrician and Gynaecologist, Bradford. 